\title{
A Study on the Sharing Economy Logistics City Model and Implementation Plan of Incheon
}

\author{
Kui-Hwa Park ${ }^{1}$ \\ ${ }^{1}$ Assistant Professor, Global Business Administration Department, Chungwoon University, South \\ Korea,khpark@chungwoon.ac.kr
}

\begin{abstract}
Resource sharing has been attracting attention since the emergence of many start-up businesses that rent and share each other's resources through an information technology-based marketplace. Now that the sharing economy is bringing about a new change in the name of shared logistics, it is necessary to change the perception of the logistics industry. If the concept of the sharing economy is applied to the logistics industry with a high proportion of fixed assets and infrastructure, it will provide an opportunity to create new profits for SMEs with relatively poor access to resources. In addition, in cities including ports and airports with various logistics resources, a systematic approach to shared logistics is required in terms of resource accessibility restrictions and availability of idle resources. The purpose of this study was to find an approach to implementing shared logistics in cities such as Incheon, and the method of analyzing cases in the literature and the Internet was used. In this study, the 25 shared logistics cases investigated were classified according to shared resources, accessibility and security, and ease of resource acquisition. Sharing of logistics resources (logistics equipments, logistics centers, airport/port facilities), open environment, and sharing using idle resources were found to be high. Based on these implications, the four sharing economy logistics city models and implementation plans were presented in order for Incheon's sharing economy logistics approach (a shared model centered on living logistics, an airport/port logistics resource sharing model, a shared model centered on urban logistics, and an airport/port facility resource sharing model).
\end{abstract}

Keywords: Sharing Economy, Sharing Logistics, Cassification of Logistics Sharing, Port Logistics Sharing Model

\section{Introduction}

Resource sharing is attracting attention with the emergence of information technology that seamlessly connects shared information and vitalization of the sharing economy. The sharing economy has grown along with the development of technology, making it possible to use idle assets more efficiently and creatively. Furthermore, completely new types of businesses are emerging, not simply utilizing idle assets. The technologies and business models that enable the sharing economy can be applied to all industries, and the logistics sector with a high proportion of fixed assets and infrastructure is no exception. Shared logistics starts with taking a step back from the existing point of view and thinking about how idle assets can be utilized. Now that the sharing economy is bringing about a new change in the name of shared logistics, it is necessary to change the perception of the logistics industry. It will be necessary to establish a sharing form with logistics characteristics applied at the crossroads toward the sharing economy type logistics era through changes to the existing logistics system by actively utilizing the surplus of unused space, unused transportation assets, and people with spare time. If the concept of

Received: September 12, 2021; $1^{\text {st }}$ Review Result: October 26, 2021; $2^{\text {nd }}$ Review Result: December 15, 2021 Accepted: January 29, 2022 
the sharing economy is applied to the logistics industry with a high proportion of fixed assets and infrastructure, it will provide an opportunity to create new profits for SMEs with relatively poor access to resources. However, cities such as ports and airports with various logistics resources require a systematic approach to shared logistics, unlike simple sharing of idle facilities in terms of resource access restrictions and idle resource availability. The purpose of this study is to present a shared economy logistics city model and to propose a plan for integrating shared logistics with Incheon, which includes ports and airports, in terms of resource accessibility and resource availability. For this purpose, this study investigated and analyzed cases of application of shared logistics through domestic and foreign literature studies and internet sites. By organizing the cases of shared logistics according to the type of sharing of logistics resources, accessibility of resources, and ease of acquisition of resources, implications were presented for shared logistics implementation models and methods in cities with airport/port facilities and general logistics facilities such as Incheon.

\section{Sharing Economy and Shared Logistics}

\subsection{Sharing Economy Concept and Classification}

\subsubsection{Sharing Economy Concept}

The sharing economy is an economic model that improves efficiency by sharing and using assets or services with others using platforms. Innovative P2P sharing economy models are spreading in various fields such as transportation and accommodation as a real-time transaction environment between individuals recently created through mobile devices.

In the early 1980s, when the term sharing economy was coined 30 years ago, the United States was experiencing a severe depression with rising unemployment rates. As a way to overcome this, Harvard Professor Martin L. Weitzman published a paper titled 'The Sharing Economy: Conquering Stagflation'. The sharing economy was proposed as a countermeasure against stagflation in the United States, and the specific concept of the sharing economy was completed in 2008 by Professor Lawrence Lessig of Harvard University in the United States[1]. It is a concept in contrast to the 'commercial economy'. In the commercial economy, 'money' or 'price' is important, but in the sharing economy, 'money' is the most incompatible concept. From the perspective of the sharing economy, it can be said that the sharing economy is a market in which resource users generate economic benefits by sharing the remaining resources or service capabilities with individuals or companies, and this is realized by using the communication and collaboration tools called the Internet[2]. When the capitalist system succeeds and extreme productivity gains are achieved and the cost of marginal product approaches zero, there will be no need for large-scale investment firms any more, and a prosumer society where everyone is both a producer and a consumer was expected[3]. The sharing economy model was also suggested as one of the ways to improve the competitiveness of SMEs[1].

\subsubsection{Classification of the Sharing Economy}

As a criterion for classifying products or services to be shared in the sharing economy, the content of shared resources and participants are classified[4]. Classification according to participants suggests the types of subjects operating the sharing system as peer-to-peer (P2P), business-to-peer (B2P), and business-to-business (B2B). Another classification is divided into space, transport, goods, and service/knowledge based on the content of resources to be shared. Space is the most typical form of sharing economy resource represented by Airbnb, and it is a temporary rental model for parking lots, offices, and kitchens in addition to accommodation spaces. Transportation may include ride-sharing or car-sharing, represented by Uber. In order to reduce the cost of owning a car, there is a car sharing 
method between individuals, in which an individual shares their car, and there is a form in which a company buys a lot of cars and provides services to members. Goods and services/knowledge include various types of services that are traded in P2P, and there is a form of sharing food, work, finance, etc. In the report that predicted the growth of the sharing economy market, five areas of travel, car sharing, finance, human resource support, and music/video streaming were classified and presented as the type of sharing economy with the highest growth potential[5].

\subsection{Shared Logistics Concept and Classification}

\subsubsection{Shared Logistics Concept}

Due to the nature of the logistics industry, logistics resources are always moving in time and space, or there are restrictions in using them when needed. This is because the logistics industry is a networktype industry, and there is no choice but to always have idle resources at a specific point in time or space. To solve this problem, information sharing and the introduction of IT tools were recognized as the most important shared resources in the supply chain[6]. Information sharing was recognized as a competitive edge in the supply chain, not only for products, processes, inventory, resources, orders, and plans between manufacturers, but also for information sharing with logistics companies[7]. Supply chain cost, quality, time and flexibility are driven through knowledge sharing, and innovative knowledge sharing has a positive effect on company performance[8]. In addition, there is a tendency to share physical resources between organizations, which can improve supply chain performance in terms of efficiency[9], reduce costs for sustainable growth, and at the same time seek opportunities to share corporate facilities and transportation vehicles[10]. Existing studies on shared logistics has done a lot of research on information sharing and knowledge sharing in terms of supply chain management, but research from the perspective of shared logistics on physical resource sharing has been limited[11]. Shared logistics have additional drivers besides economic, environmental and technological development factors. Shared logistics are being made either due to institutional factors such as city vehicle restrictions, or due to the need for collaboration between companies and the input of public funds[4]. Shared logistics, similar to the general sharing economy, collides with the traditional model, and there are many issues to be resolved due to restrictions, security issues, and responsibility issues due to different processes between organizations[4].

\subsubsection{Classification of Shared Logistics}

The classification of shared logistics can also be divided according to the sharing entity and according to resources, like the sharing economy. According to the types of shared logistics resources, existing studies have classified them into information, transport containers, transport modes and services, logistics facilities and services, and logistics networks[4]. By analyzing the sharing economy type of logistics service, the existing logistics system was changed by actively utilizing the unused space, unused transportation assets, and the 'surplus' of those who have time. In addition, shared logistics services were divided into truly shared warehousing, transportation capacity sharing, logistics asset sharing, urban discreet warehousing, on-demand staffing, community goods on-demand, and logistics data sharing[12]. As shown in [Table 1], existing research is a case in which a certain organization participates and operates in the form of joint logistics, and most of the cases in which logistics facilities and logistics services are shared. However, public facilities such as airports and ports have limitations in accessibility and security, and unlike other facilities, additional facilities must be acquired with time and investment. In order to promote shared logistics in such an urban environment, a new classification of shared logistics is required, so existing cases were reviewed and newly classified. ICT (Information and Communication Technology) is an important resource in logistics and an essential technology for establishing hardware sharing, so it is independent as a shared resource. A resource is a case in which a 
certain group of companies participate and operate in the form of joint logistics such as transport containers, transport modes, logistics facilities, and logistics networks. In particular, as they have a close relationship with the sharing method, they were distinguished from one another. Platform (platform service) is an Internet-based technology environment that makes it easy to use the above ICT and resources, and includes services.

[Table 1] Classification of Logistics Sharing by the Type of Resource

\begin{tabular}{|c|c|c|c|}
\hline Classification & Classification of shared resources & Representative case & related research \\
\hline \multirow{5}{*}{$\begin{array}{c}\text { sharing } \\
\text { economy }\end{array}$} & $\begin{array}{c}\text { space, transport, goods, and } \\
\text { service/knowledge }\end{array}$ & Airbnb, Uber, Lyft, Socar, ofo, Quirky & $\begin{array}{c}\text { Kap Hwan Kim et } \\
\text { al.(2017) }\end{array}$ \\
\cline { 2 - 4 } & $\begin{array}{c}\text { Accommodation, transportation, finance } \\
\text { (cloud funding), space, talent }\end{array}$ & $\begin{array}{c}\text { Airbnb, Uber, Lyft, GoFundMe, Kickstarter, } \\
\text { TaskRabbit } \\
\text { travel, car sharing, finance, human }\end{array}$ & DHL(2017) \\
\hline \multirow{5}{*}{ shared logistics support, music/video streaming } & $\begin{array}{c}\text { Airbnb, Uber, Lyft, TaskRabbit, Postmates } \\
\text { transport modes and services, logistics } \\
\text { facilities and services, logistics networks }\end{array}$ & $\begin{array}{c}\text { Sweettracker, Korea Pallet Pool, Convoy, } \\
\text { Mesh Korea, UCC, Shipping Alliance }\end{array}$ & Kap Hwan Kim et \\
\cline { 2 - 5 } & $\begin{array}{c}\text { truly shared warehousing, transportation } \\
\text { capacity sharing, logistics asset sharing, } \\
\text { urban discreet warehousing, on-demand } \\
\text { staffing, community goods on-demand, } \\
\text { logistics data sharing }\end{array}$ & $\begin{array}{c}\text { Flexe, MakeSpace, Omni, Huochebang, } \\
\text { Freightos, Convoy, DHL Saloodo! }\end{array}$ & DHL(2017) \\
\hline
\end{tabular}

\section{Cases by Classification of Shared Logistics}

\subsection{Cases of ICT-based Shared Logistics}

\subsubsection{Examples of Reservation System Application}

The one-stop vehicle booking system, a truck reservation system developed in Australia, is installed and operating in several terminals in Australia, the Philippines (Manila International Container Terminal, Asian Terminals, Inc), PSA Antwerp terminal, Hong Kong, Dubai, Southampton, etc. After applying this system, despite a $26 \%$ increase in the volume of cargo during peak hours, the truck's residence time in the terminal was rather reduced[4].

\subsubsection{Examples of Blockchain-based Inventory Management System Application}

When a specific order is placed for product inventory in multiple locations, such as delivery centers and stores, the optimal withdrawal location is determined, customers can take them without any problems, and all inventory in the entire supply chain can be managed in one system[13]. The 'distribution history management system' applied by Samsung SDS to Samjin Fish Cake, a seafood processing company in Busan, transparently shares all information on the production and distribution process, from warehousing to processing, packaging, and sales[14]. IBM partnered with Wal-Mart, a large retailer, to develop a food traceability system and apply blockchain to the pork distribution system in China, which made it possible to track information [15].

\subsubsection{Examples of Application of AI-based Logistics Decision Support System}

Samsung SDS uses AI-based big data analysis platform 'Brightics' in Germany (428 stores) and Austria (53 stores) electronic product distribution stores to collect sales data for three years. By predicting demand through 30 factors such as weather, local population density, age group, income, holidays, and events, the forecasting accuracy improved by $25-28 \%$, increasing the efficiency of inventory management[16]. The Postal Service Headquarters also built a next-generation logistics 
system using advanced technologies in response to the era of the 4th industrial revolution. Based on 3.8 billion logistics data per year and 24 million daily financial transaction data, the future post office built with a big data center and ICT Tin Tin Post Office was established. Through this, we plan to seek the growth of the postal and logistics business. After opening the 'postal business big data center', it also collects and analyzes data discarded after use, such as information processed at the mail sorters at 25 postal centers nationwide and customer patterns using post office shopping, to predict mail delivery volume and postal logistics process improvement and the provision of customized services[17].

\subsection{Cases of Resource-based Shared Logistics}

\subsubsection{Examples of Sharing Transport Containers (Containers, Pallets, Chassis)}

There is a marketplace that allows exchanges of empty containers, trucks, chassis, and empty slots of ships, and serves as an information transfer supporting exchange. SynchroNet in the US also provides a site for sharing containers through the Internet[18]. LogisAll's pallet pull system standardizes the dimensions and specifications of pallets and supports different manufacturers or distributors to use pallets jointly. The Asia Pallet Pool System (APPS) was established to jointly rent and operate standard pallets in Korea, Japan, Taiwan, China, and Singapore to reduce logistics costs and rationalize logistics[19]. Palletization can realize a seamless transportation system that can use the same pallet when moving, as well as reducing logistics costs and having the direct effect of being eco-friendly.

In the port of Los Angeles, there is a case in which a chassis owned by Direct ChasisLink Inc., FlexVan Leasing Inc., and TRAC Intermodal was jointly used[20]. These three companies handle 80\% of the chassis distributed in Southern California. In the meantime, the restriction that each company can only use its own chassis has caused a lot of traffic congestion in the port, and it is contributing to reducing this. Another example is the shared use of trailers between countries, and the chassis has license plates just like vehicles, so trailers with license plates from different countries cannot be driven on roads in different countries. The Cheonil Periodic Cargo service became possible after the Korea-China-Japan Logistics Ministers' Meeting reached an agreement in order to reduce logistics costs while exporting auto parts to Nissan by implementing the double number chassis service between Korea and Japan since 2013[21]. In the case of the Rotterdam Chassis Exchange Terminal, in order to reduce congestion in the port, trucks entering and leaving the port from the outside leave the chassis and export container or take the chassis and import container at the chassis exchange terminal. Transport between the port and the chassis exchange terminal is intensively carried out at idle at night. For this, it was necessary to jointly operate the chassis among the participating carriers[22].

\subsubsection{Examples of Transportation and Service Sharing}

Mesh Korea, established in 2013, provides a service that connects offline restaurants and delivery companies, while Mesh Prime operates an integrated logistics and delivery hub by distributing driver apps using individual scooter, quick, and courier operators[23]. Convoy was founded by Dan Lewis from Amazon in early 2015, and can be said to be a truck-only Uber. It is equipped with a system that transparently sets the price according to the distance or weight of the cargo and allows the shipper to track the location of the cargo[24]. The freight bus case of the CityLog Europe project is an urban shared logistics approach that is different from the existing methods in terms of technology and operation. Transporters transport cargo trunks made of independent modules, and these modules are loaded into trucks at the downtown logistics warehouse close to the city center and run along a fixed route in the delivery area. Each module will be moved to a small truck responsible for the final last mile delivery in a defined space within the city centre. If this system is used, there is no need to build a new dedicated space for stopping and distributing trucks in the city center[25]. 


\subsubsection{Examples of City Logistics Center Sharing}

As companies appear to lower the lead time required for delivery by arranging the product storage function forward in the inner city rather than in the outskirts of the city where accessibility is poor, a shared environment in the city center is becoming necessary. Connus, a start-up, operates a logistics center operation method based on the turnover rate according to product characteristics, and operates it as a cluster concept of networked small warehouses in the downtown area, not large warehouses outside the city center. In a simple work space, the minimum additional services required for online distribution such as packing and labeling are provided in the city center with minimal equipment and space[26]. The micro-fulfillment center in the city is pursuing the efficiency of small warehouses in the city by actively applying advanced robots and automation-related technologies. Such warehouse robot startups include Takeoff Technologies in the United States and CommonSense Robotics in Israel[27][28].

\subsubsection{Examples of Shared Logistics Center Sharing}

Busan Marine Equipment Association established a shipbuilding equipment joint logistics center to jointly collect and store, deliver and transport shipbuilding equipment to be delivered to Hyundai Heavy Industries, Samsung Heavy Industries, Daewoo Shipbuilding \& Marine Engineering, and STX Offshore \& Shipbuilding, and operates a bonded warehouse. Through this, productivity is improved by $20 \%$ and storage costs are reduced by 50-60\%[29]. The Kumagai Joint Logistics Center, a representative case of joint logistics for small and medium-sized enterprises, is building and operating a standard business model for joint logistics operation based on the SLP (Standard Logistics Package) system. Through this, joint storage, unloading, and joint dispatching reduced dispatch time from 10 minutes to 10 seconds, shortened picking processing time by $24 \%$, improved storage and work efficiency by $20-30 \%$, and reduced storage space by $33 \%[30]$.

For urban logistics, Germany is promoting joint logistics through joint transport and delivery within the city and the use of information networks. The GVZ model is the most widely known among Germany's common logistics methods, and as of $2009,47 \%$ of the total cargo volume is distributed using the GVZ terminal. Before the city of Nurnberg implemented the joint logistics, the average product loading rate on trucks was about $45 \%$, but the introduction of GVZ had the effect of increasing the average product loading rate to $75 \%[30]$.

\subsubsection{Examples of Transportation Connection Center Sharing}

As an example of sharing railroad cargo yards between freight transport railroads operated by different companies, $30-50 \%$ of the number of annual shipments of each cargo in Chicago from the railroad cargo yard is between railroad cargo yards. This was pointed out as an inefficient factor of rail transport, and the shared railroad cargo yard plays a role in connecting each railroad cargo yard[4].

\subsubsection{Examples of Resource Sharing between Terminals}

In 2012, due to excessive competition to attract container traffic, unloading fees were dumped and the management balance of pier operators deteriorated. To enhance the competitiveness and efficiency of Busan Port, the berths of six Gamman/Singamman pier operators were integrated. The berth integration created a large operator, allowing two or more large container ships to dock at the same time. The transshipment cost was reduced by allowing both the deep-sea shipping company and the coastal shipping company to call on the same pier[4].

\subsubsection{Examples of Sharing Public Access Restricted Facilities in Ports and Airports}

In 2018, the Port of Rotterdam announced a plan to digitalize the entire operating environment using new technologies such as IOT, AI and cloud in partnership with global IT company IBM. This project 
is to connect the entire Rotterdam Port into one system, and through this system, all stakeholders can share the port operation system and equipment, ship operation information, environment, and cargo information in real time[31].

\subsection{Cases of Platform-based Shared Logistics}

\subsubsection{Examples of Transport Platform Sharing}

MinFragh.dk (Denmark) operates a transport sharing platform that connects end customers with more than 50 transport companies and 23,000 truckers. By inducing trucks transported by LTL (Less than Truck-Load) to FTL (Full Truck-Load) for delivery, it not only provides a relatively inexpensive delivery service to customers, but also solves problems such as traffic congestion and environmental pollution[32]. Flexport in the US provides a cloud-based freight forwarding service for shippers[33].

\subsubsection{Examples of Cargo Matching Platform Sharing}

Deliv in the U.S. is a delivery sharing platform that connects distributors and end customers using freelance transporters or riders. Delivery can be made within the desired time on the same day, and when the customer enters the desired time, the transporter or rider confirms it and delivers it directly. It was acquired by US retailer Target in May 2020[34].

\subsubsection{Examples of Logistics Service Platform Sharing}

Samsung SDS launched 'Cello Square', an open logistics platform, and recommends the optimal fare and transportation schedule that best meets the customer's shipping needs when the shipper enters certain conditions such as departure and destination. Logistics visibility is provided through the real-time cargo tracking function[35].

\section{Sharing Logistics Case Analysis and Implications for Sharing Economy Logistics City Implementation}

\subsection{Shared Logistics Case Analysis}

The 25 shared logistics cases investigated in this study were classified and organized according to shared resources, accessibility and security, and ease of resource acquisition [Table 2]. In the case of shared logistics surveyed, there were more cases of sharing logistics resources (52\%) than cases of logistics services (28\%) or ICT (20\%). In particular, as for logistics resources, the proportion of logistics equipment $(47 \%)$ was higher than that of logistics centers (38\%) or airport/port facilities (15\%). In terms of accessibility and security of shared logistics resources, the open environment $(88 \%)$ was more common than the closed environment (12\%). When the cases were analyzed in terms of the ease of acquisition of shared logistics resources, the cases of sharing using idle resources (76\%) were analyzed higher than cases of acquiring new resources (24\%). Through the case analysis of shared logistics, it will be possible to draw implications for the implementation of logistics cities such as Incheon.

[Table 2] Analysis of Logistics Sharing Cases

\begin{tabular}{|c|c|c|c|c|c|c|c|c|c|c|}
\hline \multirow[b]{2}{*}{ No. } & \multirow[b]{2}{*}{$\begin{array}{l}\text { Logistics Sharing } \\
\text { Cases }\end{array}$} & \multicolumn{3}{|c|}{ Logistics Resources } & \multirow{2}{*}{\begin{tabular}{|c|} 
Logistics \\
Services \\
Platform \\
Service
\end{tabular}} & \multirow{2}{*}{$\begin{array}{c}\text { ICT } \\
\text { Logistics } \\
\text { Information } \\
\text { System }\end{array}$} & \multicolumn{2}{|c|}{$\begin{array}{l}\text { Accessibility } \\
\text { (Security) }\end{array}$} & \multicolumn{2}{|c|}{ Ease of Resource Acquisition } \\
\hline & & $\begin{array}{l}\text { Airport/Port } \\
\text { Facilities }\end{array}$ & $\begin{array}{l}\text { General } \\
\text { Logistics } \\
\text { Center }\end{array}$ & $\begin{array}{l}\text { Logistics } \\
\text { Equipment }\end{array}$ & & & Close & Open & $\begin{array}{c}\text { "Difficulty" } \\
\text { (requires } \\
\text { investment/ime) }\end{array}$ & $\begin{array}{l}\text { "Easy" } \\
\text { (Idle } \\
\text { resource) }\end{array}$ \\
\hline 1 & $\begin{array}{c}\text { 1-stop vehicle } \\
\text { booking system }\end{array}$ & & & & & $\mathrm{O}$ & & $\mathrm{O}$ & $\mathrm{O}$ & \\
\hline
\end{tabular}




\begin{tabular}{|c|c|c|c|c|c|c|c|c|c|c|}
\hline 2 & $\begin{array}{c}\text { Samjin Fish Cake } \\
\text { Distribution History } \\
\text { Management System }\end{array}$ & & & & & $\mathrm{O}$ & & $\mathrm{O}$ & $\mathrm{O}$ & \\
\hline 3 & $\begin{array}{c}\text { WalmartPork } \\
\text { Distribution System }\end{array}$ & & & & & $\mathrm{O}$ & & $\mathrm{O}$ & $\mathrm{O}$ & \\
\hline 4 & $\begin{array}{l}\text { Electronic product } \\
\text { demand forecasting } \\
\text { inventory } \\
\text { management system }\end{array}$ & & & & & $\mathrm{O}$ & & $\mathrm{O}$ & $\mathrm{O}$ & \\
\hline 5 & $\begin{array}{c}\text { Postal business big } \\
\text { data service }\end{array}$ & & & & & $\mathrm{O}$ & & $\mathrm{O}$ & $\mathrm{O}$ & \\
\hline 6 & $\begin{array}{c}\text { SynchroNet } \\
\text { (container sharing } \\
\text { site) }\end{array}$ & & & & $\mathrm{O}$ & & & $\mathrm{O}$ & & $\mathrm{O}$ \\
\hline 7 & Pallet pull system & & & $\mathrm{O}$ & & & & $\mathrm{O}$ & & $\mathrm{O}$ \\
\hline 8 & $\begin{array}{l}\text { Asia Pallet Pool } \\
\text { System }\end{array}$ & & & $\mathrm{O}$ & & & & $\mathrm{O}$ & & $\mathrm{O}$ \\
\hline 9 & $\begin{array}{c}\text { LAPort Chassis } \\
\text { Shared }\end{array}$ & & & $\mathrm{O}$ & & & & $\mathrm{O}$ & & $\mathrm{O}$ \\
\hline 10 & $\begin{array}{c}\text { Korea-Japan trailer } \\
\text { sharing }\end{array}$ & & & $\mathrm{O}$ & & & & $\mathrm{O}$ & & $\mathrm{O}$ \\
\hline 11 & $\begin{array}{c}\text { Chassis exchange } \\
\text { terminal }\end{array}$ & & & $\mathrm{O}$ & & & $\mathrm{O}$ & & & $\mathrm{O}$ \\
\hline 12 & $\begin{array}{c}\text { Mesh Korea } \\
\text { Delivery Service }\end{array}$ & & & & $\mathrm{O}$ & & & $\mathrm{O}$ & & $\mathrm{O}$ \\
\hline 13 & $\begin{array}{l}\text { Convoy truck linkage } \\
\text { service }\end{array}$ & & & & $\mathrm{O}$ & & & $\mathrm{O}$ & & $\mathrm{O}$ \\
\hline 14 & $\begin{array}{l}\text { CityLog Europe } \\
\text { Project }\end{array}$ & & & $\mathrm{O}$ & & & & $\mathrm{O}$ & & $\mathrm{O}$ \\
\hline 15 & $\begin{array}{c}\text { Small city distribution } \\
\text { center }\end{array}$ & & $\mathrm{O}$ & & & & & $\mathrm{O}$ & & $\mathrm{O}$ \\
\hline 16 & $\begin{array}{c}\text { Shipbuilding } \\
\text { Equipment Joint } \\
\text { Logistics Center }\end{array}$ & & $\mathrm{O}$ & & & & & $\mathrm{O}$ & & $\mathrm{O}$ \\
\hline 17 & $\begin{array}{l}\text { Kumagai Joint } \\
\text { Logistics Center }\end{array}$ & & $\mathrm{O}$ & & & & & $\mathrm{O}$ & & $\mathrm{O}$ \\
\hline 18 & GVZmodel & & $\mathrm{O}$ & & & & & $\mathrm{O}$ & & $\mathrm{O}$ \\
\hline 19 & $\begin{array}{c}\text { Sharing railroad } \\
\text { cargo yards }\end{array}$ & & $\mathrm{O}$ & & & & & $\mathrm{O}$ & & $\mathrm{O}$ \\
\hline 20 & dock berthintegration & $\mathrm{O}$ & & & & & $\mathrm{O}$ & & & $\mathrm{O}$ \\
\hline 21 & $\begin{array}{l}\text { Digitization of port } \\
\text { operations }\end{array}$ & $\mathrm{O}$ & & & & & $\mathrm{O}$ & & $\mathrm{O}$ & \\
\hline 22 & $\begin{array}{c}\text { Transport sharing } \\
\text { platform }\end{array}$ & & & & $\mathrm{O}$ & & & $\mathrm{O}$ & & $\mathrm{O}$ \\
\hline 23 & $\begin{array}{c}\text { Cargo forwarding } \\
\text { platform }\end{array}$ & & & & $\mathrm{O}$ & & & $\mathrm{O}$ & & $\mathrm{O}$ \\
\hline 24 & $\begin{array}{l}\text { Shipping Sharing } \\
\text { Platform }\end{array}$ & & & & $\mathrm{O}$ & & & $\mathrm{O}$ & & $\mathrm{O}$ \\
\hline 25 & Logistics platform & & & & $\mathrm{O}$ & & & $\mathrm{O}$ & & $\mathrm{O}$ \\
\hline
\end{tabular}

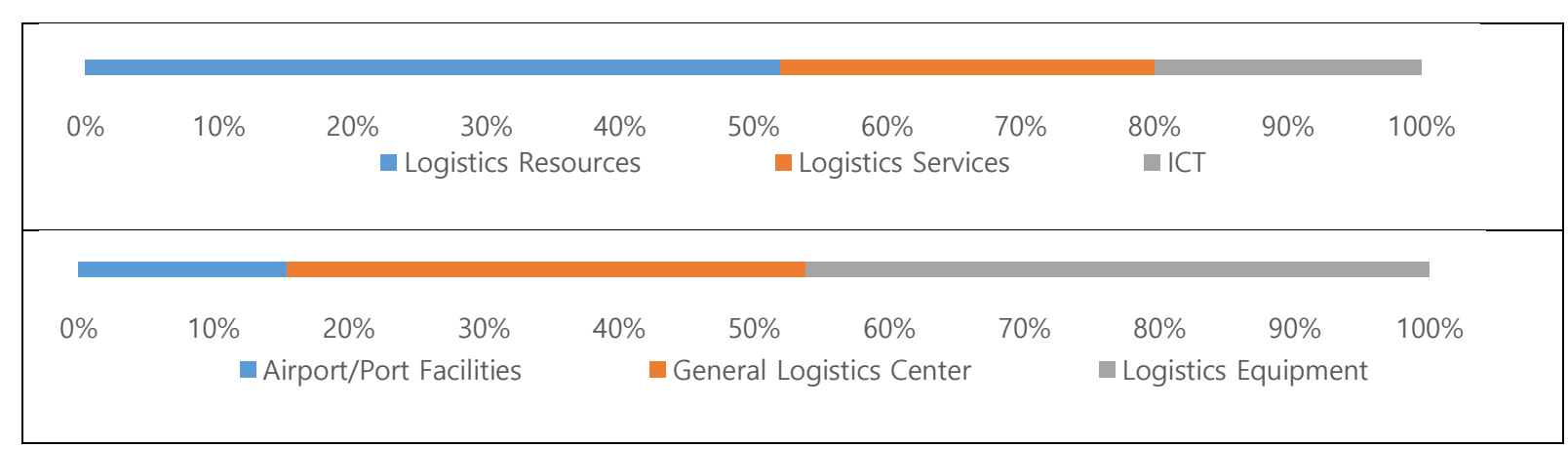




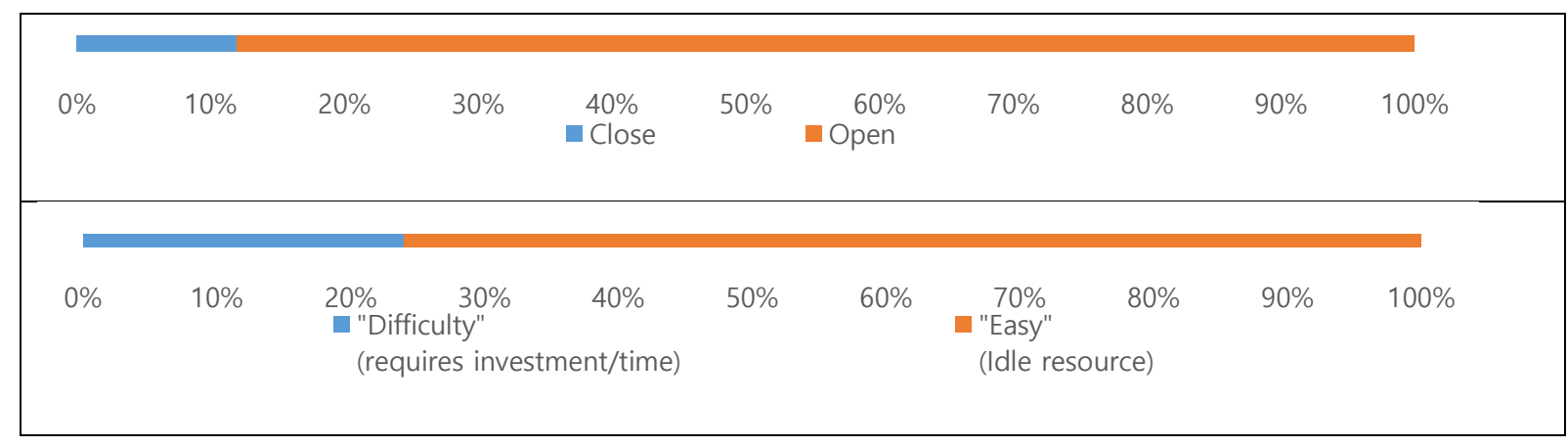

[Fig. 1] Logistics Sharing Case Analysis Result

\subsection{Implications of Sharing Economy Logistics City through Sharing Logistics Case Analysis}

Most of the existing shared logistics cases are shared logistics facilities and logistics services in the form of joint logistics. The sharing economy logistics city of Incheon considered in this study has special facilities such as airports and ports, which have limitations in accessibility and security. Also, unlike other facilities, time and investment must be accompanied to acquire additional facilities. However, since the sharing of idle resources is common in the case, it will be necessary to proceed with the general shared logistics case first and sequentially proceed with the shared logistics for the airport/port facilities in the direction of implementation of Incheon's shared economy logistics city. In addition, it was possible to draw implications through case analysis to prioritize the shared logistics of logistics resources, such as logistics equipment, logistics facilities, and airport/port facilities, rather than ICT or logistics services.

\section{Incheon Sharing Economy Logistics City Implementation Plan}

\subsection{Status of Incheon Shared Logistics and Logistics Infrastructure}

Most of the existing shared logistics in Incheon was implemented from the point of view of SMEs' common logistics facilities. There is a joint logistics center in Namdong, which opened in 2010, and joint logistics facilities such as the Incheon Port Joint Logistics Center and Incheon Public CFS are being operated as other logistics joint projects. However, most of these joint logistics projects were government-led and public-led projects, and there were limitations in their sustainability as they were not led by the private sector[36]. In addition, most of them were limited to sharing storage space in common logistics centers, so the cases of sharing idle logistics resources or implementing them as platforms for the sharing economy were limited. A systematic approach to the promotion direction and implementation plan of a shared economy logistics city that can utilize the advantages of Incheon's airport and port logistics facilities and infrastructure by benchmarking existing shared logistics cases is required.

\subsection{Incheon Shared Logistics City Model}

In order to implement shared logistics in consideration of facilities such as airports and ports, it is necessary to consider the accessibility of logistics resources and the availability of logistics facilities. Therefore, a shared logistics model that divides the logistics area of a general city and the logistics area of an airport/port is required. In this study, access to logistics resources is divided into those that can be used by anyone (Open) and those that are limited (Close), and divided into existing idle resources and new investment resources according to time and capital input to acquisition logistics resources. Based on these criteria, four models were derived: shared model centered on living logistics, airport/port 
logistics resource sharing model, urban logistics-centered sharing model, and airport/port facility resource sharing model. Considering the ease of implementation, the model approach was presented sequentially (see [Fig. 2]).

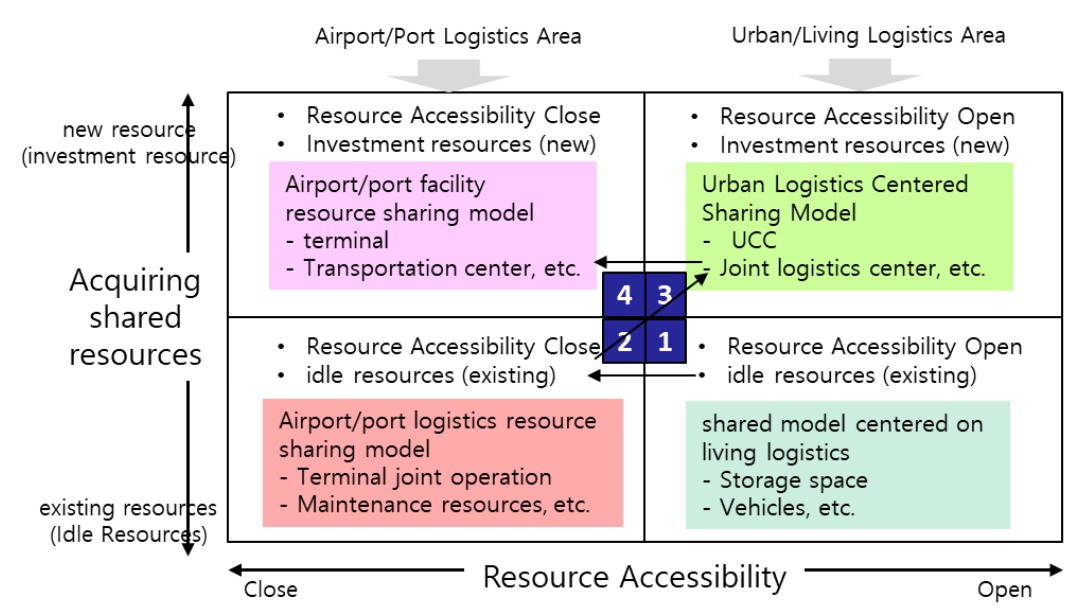

[Fig. 2] Airport/Seaport/City Shared Logistics Model

\subsubsection{Implementation Plan for Sharing Model Centered on Living Logistics}

For shared model centered on living logistics, it is first necessary to identify and discover logistics resources, and for this, it is required to establish an integrated logistics database with public-private cooperation. It is important to support platform-based logistics startup activities that can systematically manage and commercialize idle resource information on logistics resources. Institutional improvement is needed to resolve conflicts of interest with the sharing economy logistics and existing logistics companies. To this end, it is necessary to establish a periodic data management plan by collecting integrated logistics information linking companies and related organizations to identify and manage information on Incheon logistics resources and turning it into a logistics resource. In order to support the activities of logistics startups based on the sharing economy, Incheon City is required to form and support a startup atmosphere in consideration of the existing logistics market environment, where it is difficult for startups to enter the market, and the limitations of the logistics sector, such as complex laws and regulations. The city of Incheon operates a logistics manpower registration system that utilizes citizens' idle time. It is partnering with Incheon City and companies such as Baemin Connect, Coupang Flex, and Barogo Flex. It is necessary to guarantee necessary systems such as reliable manpower support to the company and customers, preparation of registration standards that guarantee identity, and an insurance system.

\subsubsection{Implementation Plan for Airport/Port Logistics Resource Sharing Model}

Airports/ports are operated separately for each terminal and are in competition with each other, but it is necessary to come up with a plan to share them if necessary. Information sharing environment for berths, yards, and yard equipment is required. It is necessary to improve airport/port operation efficiency by building a database and sharing platform that can share idle resources of airport/port logistics resources. In order to share the resources of the terminal, it is necessary to improve the operating system, such as the integration of operators. To this end, it is necessary to manage the sharing platform for idle facilities and equipment of Incheon Airport/Port in real time with Incheon City and the Port Authority as the main body. Terminals at airports/ports are major national facilities, and in order to quickly and efficiently operate containers, sharing information such as work schedules and work progress, sharing containers and transportation means, sharing logistics facilities, logistics equipment and logistics 
personnel is needed.

\subsubsection{Implementation Plan for Urban Logistics-Centered Sharing Model}

For urban logistics efficiency, building a flexible logistics network that can respond flexibly to customer needs will be a key competitive factor, breaking away from the rigid logistics network where individual logistics companies owned or dedicated hardware and software such as various logistics equipment. The city of Incheon will improve urban logistics by installing the Urban Consolidation Center (UCC) to improve the efficiency of delivery and environmental issues in the city. It is necessary to introduce a common logistics center based on a shared logistics platform to support logistics for smallscale distribution/manufacturers in Incheon and to prepare small and medium-sized logistics companies for the 4th industrial revolution. To this end, it is necessary to operate the joint collection center, which is jointly used by various courier and logistics companies in Incheon, with the support of the government or Incheon City. It is necessary to analyze and organize overseas UCC operation cases to create a shared logistics ecosystem by activating the linkage between the joint collection center and last mile delivery. Private and office buildings, public parking lots, and remaining idle spaces under city overpasses should be registered and considered for sharing as urban freight transportation infrastructure. A new joint logistics center in the form of a cooperative, supported by the government and Incheon City, will be established to acquire the role of platform operation for logistics startups and the operational capability of small and medium-sized logistics companies. And, if necessary, form an ICT-based logistics automation building technology sharing council.

\subsubsection{Implementation Plan for Airport/Port Facility Resource Sharing Model}

Unlike general logistics resources, alternatives are limited for airport/port facilities, and new ports and airports must be acquired through construction if necessary. Another method is to improve efficiency by installing an inland container depot (ICD) and a chassis exchange terminal to reduce the level of congestion in the facility. Incheon City needs support for new investment in airport/port terminal facilities and resources or investment in related facilities. To this end, in order to reduce transport congestion for terminals at ports/airports, software approaches that support information sharing, such as truck reservation systems, should be utilized first. In cases where there is not enough land behind a port/airport like Incheon, it is necessary to acquire an inland base to solve the problem of space shortage. In addition, it is necessary to prepare a plan to link the inland container depot and the chassis exchange terminal. When constructing additional airports and ports in Incheon or re-establishing the operating system, it is necessary to consider the design of the infrastructure and the design of the shared logistics platform in consideration of shared logistics. Incheon Airport and Ports will further expand the linkage of international logistics with the development of the 4th industrial technology, and the role of the nextgeneration international logistics hub such as sharing means of transportation between countries and sharing of means of robot transportation should also be considered.

\section{Conclusions}

Unlike general city shared logistics implementation strategies, Incheon has additional considerations for shared logistics implementation as important logistics facilities such as airports and ports are located. It is necessary to prepare an implementation strategy for a shared logistics city by classifying the implementation model as an investment factor for airport and port resource accessibility and facility security. This study proposes a discriminatory approach in the order of implementation, starting with sharing of idle facilities or resources in a general city, and considering new construction of airports/ports or ways to link external resources. The contribution of this study classifies the contents in the case 
analysis of shared logistics and structures them into ICT, logistics resources, and platforms, and applies and systematizes them as an implementation plan for the shared economy logistics city of Incheon. This study has limitation such that it failed to present an implementation approach as an analysis method through a case study, and an empirical analysis of what factors are necessary in the future implementation stage will be required.

\section{Acknowledgments}

This work was supported by the 2021 academic research grant fund of Chungwoon University.

\section{References}

[1] Kang Bae Lee, Hyung Rim Choi, Soon Goo Hong, Min Je Cho, Development of a Sharing Economic Model for the Competitiveness of SMEs, Entrue Journal of Information Technology, (2015), Vol.14, No.1, pp.93-105, UCI: G704001673.2015.14.1.008

[2] M. Olson, S. J. Kemp, Sharing Economy: An In-depth Look at Its Evolution and Trajectories across Industries, Piper Jaffray Investment Research, pp.1-7, (2015)

[3] S. J. Jeong, T. Lee, A Study on Share-based Industrial Policy for Small and Medium-sized Logistics Businesses, The Korea Transport Institute, pp.10-13, (2013)

[4] Kap Hwan Kim, Xuefeng Jin, Chang Hoon Woo, A Survey on Sharing Economy and Logistics Resources Sharing, Journal of the Korean Society of Supply Chain Management, (2017), Vol.17, No.2, pp.89-115, DOI: http://dx.doi.org/10.25052/KSCM.2017.10.17.2.89

[5] Consumer Intelligence Series: The Sharing Economy, PricewaterhouseCoopers, pp.7-12, (2015) http://www.pwc.com/us/en/industry/entertainment-media/publications/consumer-intelligence-series/assets/pwc-cissharing-economy.pdf

[6] D. Simchi-Levi, P. Kaminsky, E. Simchi-Levi, Designing and Managing the Supply Chain: Concepts, Strategies and Case Studies, McGraw-Hill, pp.221-238, (2000)

[7] L. Rivera, D. Gligor, Y. Sheffi, The benefits of logistics clustering, International Journal of Physical Distribution \& Logistics Management, (2016), Vol.46, No.3, pp.242-268, DOI: https://doi.org/10.1108/IJPDLM-10-2014-0243

[8] P. J. Singh, D. Power, Innovative knowledge sharing, supply chain integration and firm performance of Australian manufacturing firms, International Journal of Production Research, (2014), Vol.52, No.21, pp.6416-6433, DOI: https://doi.org/10.1080/00207543.2013.859760

[9] D. Gong, S. Liu, X. Lu, Modelling The Impacts Of Resource Sharing On Supply Chain Efficiency, International Journal of Simulation Modelling, (2015), Vol.14, No.4, pp.744-755, DOI: 10.2507/IJSIMM14(4)CO20

[10] S. Islam, T. Olsen, Truck-sharing challenges for hinterland trucking companies: A case of the empty container truck trips problem, Business Process Management Journal, (2014), Vol.20, No.2, pp.290-334, DOI: https://doi.org/10.1108/BPMJ-03-2013-0042

[11] Barbara Ocicka, Grażyna Wieteska, Sharing economy in logistics and supply chain management, LogForum, (2017), Vol.13, No.2, pp.183-193, DOI:10.17270/J.LOG.2017.2.6

[12] Sharing Economy Logistics, DHL pp.15-25, (2017)

[13] DEPOSCO, http://deposco.com, Sep 20 (2021)

[14] https://www.mk.co.kr/news/business/view/2018/03/154253/, Sep 20 (2021)

[15] https://zdnet.co.kr/view/?no=20170824102742, Sep 20 (2021) 
[16] https://biz.chosun.com/site/data/html_dir/2018/03/08/2018030801626.html, Sep 20 (2021)

[17] http://www.postnews.kr/cpost_news/sub_read.asp?cate=28\&BoardID=1867, Sep 20 (2021)

[18] https://synchronet.co/, Sep 20 (2021)

[19] http://www.logisall.co.kr/main/main.asp, Sep 20 (2021)

[20] https://www.joc.com/trucking-logistics/drayage/trac-intermodal-form-its-own-la-long-beach-chassispool_20150402.html, Sep 20 (2021)

[21] http://www.monthlymaritimekorea.com/news/articlePrint.html?idxno=12648, Sep 20 (2021)

[22] Dekker, R., van der Heide, S., van Asperen, E., Ypsilantis, P. A Chassis Exchange Terminal to Reduce Truck Congestion at Container Terminals, Flexible Services and Manufacturing Journal, (2013), Vol.25, No.4, pp.528-542, DOI:10.1007/s10696-012-9146-3

[23] https://meshkorea.net/kr/index.html, Sep 20 (2021)

[24] https://convoy.com/, Sep 20 (2021)

[25] Sung Ho Hur,Yeonjoo Min, Boo Sun Choi, Sebeom Park, Strategies for the implementation of city logistics public standard platform to improve parcel delivery service quality, , The Korea Transport Institute, pp42-55, (2016)

[26] https://connus.co.kr/index\#, Sep 20 (2021)

[27] https://www.takeoff.com/, Sep 20 (2021)

[28] http://www.irobotnews.com/news/articleView.html?idxno=17702, Sep 20 (2021)

[29] http://www.kbiznews.co.kr/news/articleView.html?idxno=43324, Sep 20 (2021)

[30] http://www.ulogistics.co.kr/ulogistics/board.php?board=special\&command=body\&no=362, Sep 20 (2021)

[31] https://www.mk.co.kr/news/economy/view/2018/12/811895/, Sep 20 (2021)

[32] SangHwa Song, A Study on the Policy to Activate the Logistics Industry Using ICT, Korea International Trade Association, p.57, (2016)

[33] https://www.flexport.com/, Sep 21 (2021)

[34] https://techcrunch.com/2020/05/07/target-is-looking-to-buy-delivs-same-day-delivery-tech/, Sep 21 (2021)

[35] https://www.cellosquare.com/kr-ko/index.do, Sep 21 (2021)

[36] JuYoung Yu, MyungHwa Lee, Study on the Revitalization Plan of Logistics Cooperation of Small and Medium Enterprises in Incheon, Incheon Development Institute, pp.77-110, (2014) 